\title{
Use of alternative-complementary-medicine (CAM) in Calabrian children
}

Teresa Rita Dolceamore ${ }^{1}$, Federica Altomare ${ }^{2}$, Francesco Zurlo ${ }^{2}$ and Roberto Miniero ${ }^{2^{*}}$

\begin{abstract}
Objective: The use of complementary and alternative medicine (CAM) has not been widely studied among children in Italy. ISTAT-2005 survey showed a prevalence of 10\% concerning children treated with CAM. The lack of data about the use of CAM in pediatrics in the South of Italy aimed us to conduct an epidemiological inquiry in Calabria.

Methods: The study has been conducted from 2009 and 2011 at the Pediatric Units of: University "Magna Graecia"- Catanzaro (CZ), Pugliese-Ciaccio Hospital-Catanzaro (CZ), Annunziata Hospital-Cosenza (CS), Jazzolino Hospital- ViboValentia (W), Riuniti Hospitals- Reggio Calabria (RC) and San Giovanni di Dio Hospital- Crotone (KR). All information was collected through a questionnaire proposed to children's parents admitted to these hospitals as out-patients or in-patients.
\end{abstract}

Results: 1387 parents were approached to complete the questionnaire. 21(1,5\%) refused to answer. A total of 1366 questionnaire was analyzed: 378 at CZ, 450 at CS, 131 at KR, 201 at W and 206 at RC, with a response rate of 98,5\%. In total, the percentage of children using CAM varied from 18\% in Crotone to 38\% in Cosenza. The parents who used CAM for their children were older and with a higher education. Phytotherapy was preferred to homeopathy. The gastrointestinal pathologies and upper respiratory tract are those ones for which frequently parents recur to CAM. Of note we have not to disregard their use " to strengthen" the immune system. In most of cases CAM have been prescribed by pediatrician.

Conclusions: Our study remarks that the use of CAM is increased dramatically among the calabrian children in the last years as well as in other countries. Pediatricians need to improve their knowledge about CAM in order to better manage the parental attitude.

\section{Introduction}

According to the National Centre for Complementary and Alternative Medicine (NCCAM), considered the leading institution providing studies and informations on these practices, Complementary and Alternative Medicine (CAM) are defined as "preparations and practices that are not regarded as a part of conventional medicine and which may be used as complement or as an alternative to conventional medicine" [1].

In the USA the recourse of CAM is very extended in adults (up to $70 \%$ of them use some form of CAM) [2-5]. An increase of CAM (30\% - 40\% of the population) has been observed in Europe during the last two decades. The United Kingdom is the country which boasts the

\footnotetext{
* Correspondence: roberto.miniero@unicz.it

${ }^{2}$ Università Magna Graecia di Catanzaro, Catanzaro, Italy

Full list of author information is available at the end of the article
}

greatest historical tradition, but also in France and Germany the use of CAM is common among adults; in these countries CAM are regularly interconnected with Conventional Medicine, as they are integrated in the Universities and in the Public Health [2-5].

The European Project CAMbrella has been recently approved in order to build a research network for CAM; it encompass 16 academic research groups from 12 countries (Italy included) [6].

Available data for Italy are poor. Two researches of National Institute of Statistics (ISTAT), which were performed at the end of the 90's and in 2005 recorded a prevalence of $15,5 \%$ and of $13,6 \%$, respectively. Homeopathy was the most used kind of CAM, followed by hand treatments, phytotherapy and acupuncture. CAM are more common in the regions of Northern Italy [7]. In Tuscany, which represents the region where the unconventional treatments

\section{Biomed Central}


have a major spread and where they are recognized also by the National Health Service (SSN), the prevalence of CAM users is 15 to $20 \%$, but $45 \%$ of the surveyed population consider useful at least one type of CAM $[8,9]$.

International data about the use of CAM in pediatrics regard almost exclusively American and North European children. The prevalence of CAM use among children varies between $9 \%$ and $70 \%$ depending on the definition of CAM; the use is more frequent among those children with a parent who use CAM and among children suffering from chronic illness as tumors, juvenile rheumatoid arthritis, asthma and inflammatory bowel disease [10-28]. Far less is available concerning CAM use among children in the general population. A recent study in Germany remarked a rate of homeopathy use equal to $7,5 \%$ and phytotherapy one equal to $30,6 \%$ [29]. In Finnish population the prevalence of children CAM users was $10 \%$ and in Wales $41 \%$ [30,31].

Italian data about the use of CAM in pediatrics are few and they were achieved by researches in the Northern regions exclusively; this fact draws the line at the correct interpretation of the phenomenon [7-9,25,32]. The lack of data in the South of Italy aimed us to explore the patterns of CAM among a general population of Calabrian children, investigating the frequency and the type of CAM, the socio-demographic factors, the diseases treated with CAM and finally the perceived helpfulness and risk of side effect.

\section{Methods}

The study has been carried out from 2009 to 2011 at the Pediatric Units of: University "Magna Graecia"-Catanzaro (CZ), Pugliese-Ciaccio Hospital- Catanzaro (CZ), Annunziata Hospital-Cosenza (CS), Jazzolino Hospital -ViboValentia (VV), Riuniti Hospitals- Reggio Calabria (RC) and San Giovanni di Dio Hospital- Crotone (KR).

All the information was collected through a questionnaire proposed to the parents of children admitted to these hospitals as out-patient or as in-patients. The definition of CAM is not homogeneous. In this survey only the CAM accepted by FNOMCEO were considered: homeopathy, phytotherapy, acupuncture, chiropractic, osteopathy, traditional Chinese medicine, antroposohycal medicine [33].

Data collection was based on a structured questionnaire, proposed vis-à-vis to the parents of young patients. It included questions about demographic characteristics of parents, diseases treated with of CAM, type of CAM, prescription, satisfaction and side effect observed.

The interviewers- students of 6th year University Medicine course, or young physician of the Pediatric School - have been trained in basic techniques of communication. The training of interviewers makes it more valid the comparison of data collected and their potential of information, as it is inevitable that the difference between different interviewers influences the responses to the questionnaire, through the effect known as "expectation effect": the training of interviewers was intended to minimize this effect on the research.

In the field of experimental sciences and statistics we refer to 'expectancy effect (or Rosenthal effect) when referring to the distortion of the results of an experiment due to expectations that the researcher and / or experimental subjects have on the results of the experiment. [34]. With regard to the interviewer mentions the so called "interviewer error": a systematic error, related to the more or less aware selectivity of the data collection. Philipps and Clancy speak about modeling effects referring to the generality of the distortions produced by the interviewer using verbal and nonverbal (gestures, body posture, eye movements, tone of voice, pauses, etc.) [35]. The training of interviewers covered each of these aspects, with particular regard to the prosodic aspects, the use of the gaze, physical contact, managing questions, doubts and objections. The importance of interviewers training for the purposes of this research is also tied to the dual role of these. Responsibility of the interviewers was indeed also to give parents a detailed explanation of the topics examined in order to facilitate understanding and orientate the compilation (once again at the expense of comparability and therefore of their power and heuristic information). The training was conducted by a psychologist expert of communication. Before administration of the questionnaire a detailed description of the topic was provided to the parent. A written informed consent was obtained from the patient's parents for publication of this report.

\section{Results}

One thousand three-hundred eighty seven parents (primarily the mother) were approached to complete the questionnaire. Twenty one parents $(1,5 \%)$ refused to answer, resulting in a total of 1366 questionnaires for analysis: 378 at CZ, 450 at CS, 131 at KR, 201 at VV and 206 at RC, with a cumulative response rate of $98,5 \%$.

Outline the socio-demographic data of the parents interviewed. CAM users were more aged and with higher level of education than non-users. The difference was more evident for mother than for father. The features of the parents who filled in the questionnaire are summarized in Table 1.

In total, the percentage of children using CAM ranged from $18 \%$ in Crotone to $38 \%$ in Cosenza (Figure 1). Phytotherapy was more utilized than homeopathy. No other modalities of CAM were used (Figure 2).

The most common illness treated with CAM were gastrointestinal diseases, upper respiratory tract diseases 
Table 1 Characteristics of the study population

\begin{tabular}{|c|c|c|c|c|c|c|c|c|c|c|}
\hline \multirow{2}{*}{$\begin{array}{l}\text { Town } \\
\text { CAM user } u\end{array}$} & \multicolumn{2}{|c|}{$\mathrm{CZ}$} & \multicolumn{2}{|c|}{ CS } & \multicolumn{2}{|c|}{ VV } & \multicolumn{2}{|c|}{ KR } & \multicolumn{2}{|c|}{$\mathrm{RC}$} \\
\hline & Yes & No & Yes & No & Yes & No & Yes & No & Yes & No \\
\hline Mother's mean age & 40 & 35 & 39 & 35 & 31 & 36 & 36 & 36 & 36 & 36 \\
\hline Father's mean age & 48 & 40 & 42 & 41 & 41 & 38 & 41 & 39 & 39 & 39 \\
\hline \multicolumn{11}{|l|}{ Mother's instruction } \\
\hline Elementary/middle school & $29 \%$ & $46 \%$ & $26 \%$ & $41 \%$ & $23 \%$ & $47 \%$ & $48 \%$ & $50 \%$ & $25 \%$ & $48 \%$ \\
\hline High school & $53 \%$ & $45 \%$ & $50 \%$ & $43 \%$ & $65 \%$ & $38 \%$ & $39 \%$ & $40 \%$ & $36 \%$ & $37 \%$ \\
\hline University degree & $18 \%$ & $9 \%$ & $23 \%$ & $15 \%$ & $12 \%$ & $15 \%$ & $13 \%$ & $9 \%$ & $39 \%$ & $15 \%$ \\
\hline \multicolumn{11}{|l|}{ Father's instruction } \\
\hline Elementary/middle school & $39 \%$ & $56 \%$ & $35 \%$ & $45 \%$ & $49 \%$ & $48 \%$ & $39 \%$ & $56 \%$ & $26 \%$ & $53 \%$ \\
\hline High school & $50 \%$ & $37 \%$ & $52 \%$ & $44 \%$ & $41 \%$ & $36 \%$ & $44 \%$ & $34 \%$ & $46 \%$ & $37 \%$ \\
\hline University degree & $12 \%$ & $7 \%$ & $13 \%$ & $11 \%$ & $10 \%$ & $14 \%$ & $18 \%$ & $8 \%$ & $26 \%$ & $7 \%$ \\
\hline Patient's mean age & 6,0 & 2,0 & 7,4 & 7,4 & 5,2 & 5,5 & 7,3 & 6,7 & 5,2 & 6,4 \\
\hline Males\% & $50 \%$ & $51 \%$ & $58 \%$ & $58 \%$ & $57 \%$ & $53 \%$ & $43 \%$ & $55 \%$ & $46 \%$ & $47 \%$ \\
\hline Females \% & $50 \%$ & $49 \%$ & $42 \%$ & $42 \%$ & $43 \%$ & $47 \%$ & $56 \%$ & $44 \%$ & $54 \%$ & $53 \%$ \\
\hline
\end{tabular}

and dermatological disease; many parents used CAM "to strengthen" the immune system. Few patients were treated with CAM for chronic diseases (Table 2).

The majority of parents feel that CAM must be prescribed by pediatrician; few of them self-initiated the use of CAM. The results are summarized in Table 3.

All the CAM users, with the exception of 3, 5\% of them in Cosenza who used only CAM for their children, were conventional medicine users too.

Perception of the efficacy of CAM was high in all interviewed. Referred side effects were few (Table 4).

\section{Discussion}

In this multicenter survey we investigated the use of CAM in children through a questionnaire filled by parents of children admitted as in-patients or as out-patients in five General Hospitals in Calabria. The properties of the questionnaires to assess CAM use in pediatrics are still an open question and this may represent an important bias for interpreting the data of the literature. A recent review by April showed as none of CAM questionnaires have been thoroughly validated. This may be explained by the relative novelty of studies in this field. In fact is difficult to collect data in a standardized way since not only there is no agreement on the definition of CAM by researchers, but also for the fact that the parent's perception of the product's nature used may be confounding [36]. For these reasons, in order to reduce the bias toward the type of CAM, we decided to limit the number of CAM considered in the survey to the CAM reported by FNOMCEO [33]. Furthermore, most studies reported in literature used a self-administered questionnaire which has significantly limitation, first of all misinterpretation of terms and concepts. In order to minimize this second bias we preferred to administrate the questionnaire vis-a-vis properly training the interviewers. The percentage of non-compliant parents was very small $(1,5 \%)$ and all

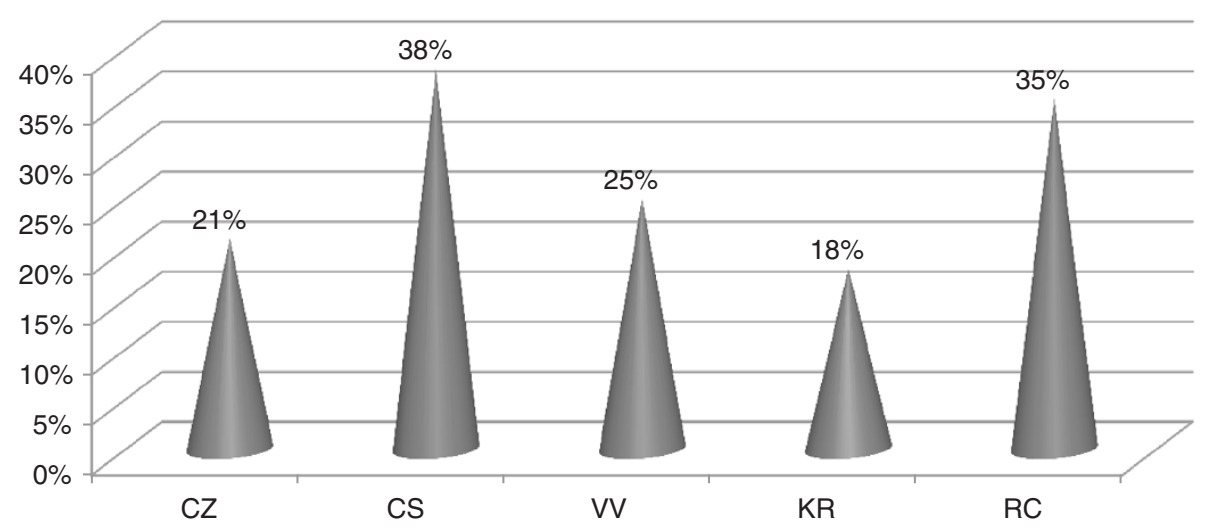

Figure 1 Percentage of patients treated with CAM. 


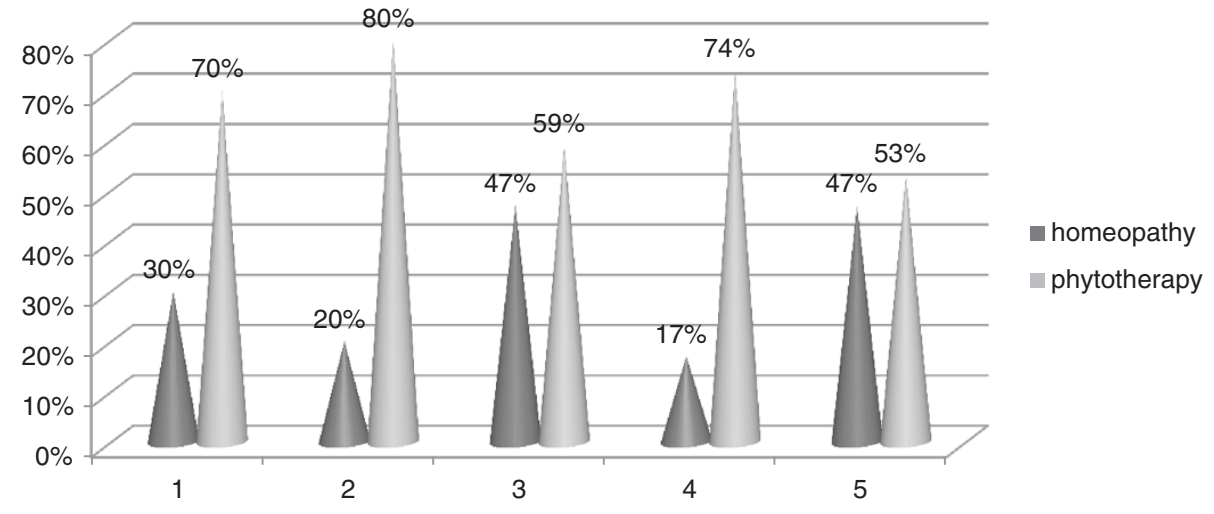

Figure 2 Type of CAM used.

the questionnaires filled in were evaluable. This confirms that the methodology we use (vis-à-vis questionnaire and trained interviewers) may represent a helpful model for these type of survey.

To the best of our knowledge, this is the first report concerning a large cohort of patients in the South of Italy. Our study shows that the use of CAM increased dramatically among the children living in southern Italy too and the percentage of patients treated with CAM is quite reaching the observed percentage in other European countries. In fact our study clearly shows that use of CAM in our Region is more common than expected, considering the results of ISTAT survey performed in 2005 , which report a nationwide percentage of $13,6 \%$ of the population [7]. The explanation for the growing use of CAM in Calabria may involve the same factors of north Italian regions and other countries: most users are dissatisfied with conventional medicine; reject technological medicine; believe that CAM had no potential adverse effects; feel they need an holistic or natural approach rather than an approach focused on specific pathogenic process (generally emphasized by conventional medicine); search for a new consideration of those

\section{Table 2 Diseases treated with CAM}

\begin{tabular}{llllll}
\hline Town & CZ & CS & VV & KR & RC \\
\hline Disease treated & & & & & \\
\hline Upper- airway diseases & $58 \%$ & $76 \%$ & $41 \%$ & $74 \%$ & $46 \%$ \\
\hline Gastrointestinal diseases & $17 \%$ & $41 \%$ & $29 \%$ & $13 \%$ & $29 \%$ \\
\hline To strenghthen immune sistem & $13 \%$ & $53 \%$ & $30 \%$ & $13 \%$ & $32 \%$ \\
\hline Teeth eruption pain & $5 \%$ & $3 \%$ & $4 \%$ & - & $3 \%$ \\
\hline Dermatological diseases & $13 \%$ & $23 \%$ & $12 \%$ & - & $8 \%$ \\
\hline Allergic disorders & - & $3 \%$ & - & - & $4 \%$ \\
\hline Sleep disorders & - & - & $8 \%$ & $17 \%$ & $1 \%$ \\
\hline Minor injures & $5 \%$ & $8 \%$ & - & $9 \%$ & $4 \%$ \\
\hline Other diseases & - & - & $2 \%$ & $13 \%$ & $7 \%$ \\
\hline
\end{tabular}

aspects often neglected - inter alia sense, communication and relation.

However in the light of the results coming from this inquiry it is possible to speculate that a slight difference exists among the five examined towns (from 18\% of Crotone to $38 \%$ in Cosenza of CAM user). It is difficult to explain these differences, as socio-economics and sociocultural back-ground are quite similar in the five populations, but it is interesting the fact that the percentage observed in Cosenza is quite similar to that one observed in our previous study in Turin (43\%) [37].

Our study agrees with the current literature: the oldest and the most educated parents are those who trust to CAM [7-9,30,38]. These results might be interpreted in the light of a longer and personal experience in the use of CAM by the oldest parents and in the light of a wider economic checking among the most educated parents. A more qualified level of education corresponds to an economically best-paid profession and this is to influence the therapeutic choices made by parents. The unconventional therapies are considered more expensive and they aren't refunded by the National Health System, with rare exceptions $[8,9]$.

The ISTAT research, in 2005, reported the use of CAM more frequent in the oldest children [7]. Our research agrees with these data as it shows that especially the oldest children use them.

The majority of the parents exploit the unconventional therapies in the same way of the conventional medicine without laying upon it, with the exception of Cosenza,

Table 3 Medical prescription required by parents for CAM

\begin{tabular}{lccccc}
\hline Town & CZ & CS & VV & KR & RC \\
\cline { 1 - 5 } Medical prescription & & & & & \\
\cline { 1 - 6 } Always required & $50 \%$ & $64 \%$ & $82 \%$ & $48 \%$ & $81 \%$ \\
\hline Required according to the disease & $47 \%$ & $27 \%$ & $16 \%$ & $48 \%$ & $21 \%$ \\
\hline Unecessary & $3 \%$ & $9 \%$ & $2 \%$ & $4 \%$ & $1 \%$ \\
\hline
\end{tabular}


Table 4 Evaluation of therapeutic success with CAM

\begin{tabular}{lccccc}
\hline Town & CZ & CS & VV & KR & RC \\
\hline In most of cases & $65 \%$ & $67 \%$ & $51 \%$ & $26 \%$ & $57 \%$ \\
\hline Some times & $19 \%$ & $28 \%$ & $41 \%$ & $61 \%$ & $35 \%$ \\
\hline Never & $15 \%$ & $5 \%$ & $6 \%$ & $13 \%$ & $7 \%$ \\
\hline Side effects & $5 \%$ & $2 \%$ & $4 \%$ & $0 \%$ & $3 \%$ \\
\hline
\end{tabular}

where an exiguous minority $(3,5 \%)$ of parents affirms they exclusively use CAM. So this common behavior agrees with the latest indications which aim at considering CAM as real complementary therapies instead of an alternative treatment to conventional therapies. This point is underscored by the observation that most of the interviewers, in case of unconventional therapies' failure, come back to refer to Official Medicine - therefore demonstrating a substantial trust in the conventional practices. The gastrointestinal pathologies and upper respiratory tract are those ones for which most frequently parents recur to CAM. We have not to disregard their use to strengthen the immune system. These data agree with literature ones [10-14]. We cannot affirm the same in regards to the use of CAM for the chronic disease. The percentage of patients with chronic illness who use CAM is, in fact, very low compared to what we highlighted in other studies [21-28]. This result may be a bias due to the fact that few patients of our study were affected by chronic disease. The low number of patients with chronic diseases may be related to the fact that our survey has been performed by interviewing in-patient and out-patient parents of General Pediatric Hospitals, not in subspeciality departments. In fact patients with severe chronic illness - i.e neoplastic diseases, cystic fibrosis, hematological diseases, asthma - usually refer to specialist departments rather than to General Pediatric Hospitals.

Homeopathy and phytotherapy are the most common CAM used in children. In some reports the first one is preferred while in other surveys the second is prevalent. Other types of CAM - as acupuncture; massage therapy; osteopathy and chiropractic remedies - are less frequently preferred by parents [10-14,17,20-22]. In Calabria when parents choose CAM, the choice exclusively concentrates on phytotherapy or homeopathy, with a prevalence of the first. These data are disagree with those observed in Turin [37] and in the other Italian regions [7-9], in which homeopathy is more widely used. We must not forget that while in Calabria CAM are prescribed more frequently by pediatricians, Northern Italian parents often opt for "self-medication" of their children [37]. We may speculate that in our region pediatricians are more confident with phytoterapy than with homeopathy. Furthermore, we cannot exclude differences in local marketing forces.
The other forms of CAM were not reported in our research. This data is in contrast with our data obtained in Turin again, and with the other data coming from other countries showing that other modalities of CAM are used. We can therefore only speculate about the reason for this findings. It might be possible that the difference reflects the lack of professional figures in Calabria involved in other types for CAM as acupuncture or kyropractice.

The satisfaction's level of the results which were achieved with CAM is high. These results agree with the previous data observed in Turin [37].

Remarkably we found that, in the most of cases, the pediatrician prescribes phytotherapic or homeopathic drug. This agrees with the data of the SIP's research, which highlighted that over a quarter of the Italian pediatricians usually prescribe this kind of medicines [39].

As the use of CAM by children and adolescent is currently in a growth phase in all countries important pediatric scientific societies are interested in them. The American Academic of Pediatric includes Provisional Section on Complementary, Holistic and Integrative Medicine [40]. The Italian Society of Pediatrics established a working-party for CAM [39]. Italian pediatricians, cannot longer ignore this situation [41-43]. They need to improve their knowledge and communication skills about CAM in order to manage the parental attitude, with regard to the potential benefit and the potential interaction, in an open non-judgmental way. If this is not so, parents and children will turn to other professional and they risk to lose the central position in the children's care.

\section{Competing interests}

The authors declare that there is not conflict of interests

\section{Authors' contributions}

TRD, FA, FZ, RM designed the study, provided data collection, wrote the manuscript. FZ designed the questionnaire and trained the interviewers. RM coordinated the work. All authors read and approved the final manuscript

\section{Other investigators}

Dr. S. Braghò, Dr. M. Crinò, Dr. A. C. Oliverio, Dr. M. Filippo, Dr. D. Lucente.

\section{Acknowledgements}

We thank the families for participation in this study. We thank Dr G. Raiola (Pugliese-Ciaccio Hospital di CZ), Dr. D. Sperlì (Annunziata Hospital of Cosenza), Dr D. Costantino (OspedaliRiuniti of Reggio Calabria), Dr. C. Procopio(Jazzolino Hospital di ViboValentia), and Dr. A. Cirisano (San Giovanni di Dio Hospital of Crotone), chiefs of the Pediatric Units, for allowing recruitment.

\section{Author details}

${ }^{1}$ Primary Care Pediatrician, Crotone, Italy. ${ }^{2}$ Università Magna Graecia di Catanzaro, Catanzaro, Italy.

Received: 10 August 2012 Accepted: 29 November 2012 Published: 11 December 2012 


\section{References}

1. National Centre for Complementary and Alternative Medicine. website Available http://nccam.nih.gov.

2. Barnes PM, Powell-Griner E, McFann K, Nahin RL: Complementary and alternative medicine use among adults: United States 2002. Adv Data 2004, 343:1-19.

3. Tindle HA, Davis RB, Phillips RS, Eisenberg DM: Trends in use of complementary and alternative medicine by US adults: 1997-2002. AlternTher. Health Med 2005, 111:42-9.

4. Eisenberg DM, Davis RB, Ettner SL, et al: Trends in alternative medicine use in the United States, 1990-1997: results of a follow-up national survey. JAMA 1998, 280:1569-75

5. Eisenberg DM, Kessler RC, Foster C, Norlock FE, Calkins DR, Delbanco TL: Unconventional medicine in the United States: prevalence, costs, and patterns of use. N Engl J Med 1993, 328:246-252.

6. Weidenhammer $W$, Lewith $G$, Falkenberg $T$, Fønnebø V, Johannessen $H$, Reiter B, Uehleke B, von Ammon K, Baumhöfener F, Brinkhaus: B.EU FP7 project 'CAMbrella' to build European research network for complementary and alternative medicine. ForschKomplementmed 2011, 18(2):69-76

7. in Italia ISTAT"Ltnc: Anno 2005. www.istat.it. Statistiche in breve. Roma 21 agosto 2007.

8. Giannelli M, Cuttini M, Arnaini S, Baldi P, Buiatti E: le medicine non convenzioanli in Toscana:attitudini e utilizzo nella popolazione. Epidemiol Prev 20014, 28(1):27-33.

9. Toscana MC: Notiziario regionale delle Medicine Complementari, Volume 19. 2010.

10. Barnes PM, Bloom B, Nahin RL: Complementary and alternative medicine use among adults and children: United States, 2007. NatlHealth Stat Report 2008, 10:1-23.

11. Davis MP, Darden PM: Use of complementary and alternative medicine by children in the US. Arch PediatrAdolesc Med 2003, 157(4):393-396.

12. Birdee GS, Phillips RS, Davis RB, Gardiner P: Factors associated with pediatric use of complementary and alternative medicine. Pediatrics 2010, 125:249-56.

13. Vlieger AM, van de Putte EM, Hoeksma H: The use of complementary and alternative medicine in children at a general paediatric clinic and parental reasons for use. Ned TijdschrGeneeskd 2006, 150:625-30.

14. Madsen H, Andersen S, Nielsen RG, Dolmer BS, Høst A, Damkier A: Use of complementary/alternative medicine among paediatric patients. Eur J Pediatr 2003, 62:334-41.

15. Gilmour C, Harrison S: Vohra. Concluding comments: maximizing good patient care and minimizing potential liability when considering complementary and alternative medicine. Pediatrics 2011, 128:S206-212.

16. Gardiner P, Riley DS: Herbs to homeopathy. Pediatr Clin North Am 2007, 54:859074.

17. Yussman SM, Ryan SA, Auinger P, Weitzman M: Visits to complementary and alternative medicine providers by children and adolescents in the United States. AmbulPediatr 2004, 45:429-435.

18. Keefe $\mathrm{M}$, Coat $\mathrm{S}$ : Increasing health-care options: the perspectives of parents who use complementary and alternative medicines. JPaediatr Child Health 2010, 46:296-300.

19. Snyder J, Brown P: Complementary and alternative medicine.an analysis of the recent literature. Curr Opin Pediatr 2012, 24:539-546.

20. Pitetti R, Singh S, Hornak D, Garcia SE, Herr S: Complementary and alternative medicine use in children. PediatrEmergCare 2001, 17:165-169.

21. Post-White J, Fitzgerald M, Hageness S, Sencer SF: Complementary and alternativemedicine use in children with cancer and general and specialty pediatrics. J PediatrOncolNurs 2009, 26:7-15.

22. Marchisio P, Bianchini S, Galeone C, Baggi E, Rossi E, Albertario G, Torretta S, Pignataro L, Esposito S, Principi N: Use of complementary and alternative medicine in children with recurrent acute otitis media in Italy. Int $\rfloor$ ImmunopatholPharmacol 2011, 24:441-9.

23. Mainardi T, Kapoor S, Bielory L: Complementary and alternative medicine: herbs, phytochemicals and vitamins and their immunologica effect. J AllergyClin/mmunol 2009, 123:283-94.

24. McCann $\sqcup$, Newell SJ: Survey of paediatric complementary and alternative medicine use in health and chronic illness. Arch Dis Child 2006, 91:173-174.

25. Shen J, Oraka E: Complementary and alternative medicine (CAM) use among children with current asthma. Prev Med 2012, 54:27-31.
26. Fadanelli G, Vittadello F, Martini G, Zannin ME, Zanonn G, Zulian F: Complementary and Alternative Medicine (CAM) in paediatric reumatology: aEuropen perspective. Clin Exp Rheumatol 2012, Feb3 (Epub ahead of print).

27. Haliloglu B, Isguven P, Yildiz M, Arslanoglu I, Erguven M: Complementary and alternative Medicine in Children with Type1 Diabetes Mellitus. J Clin Res Ped Endo 2011, 3:139-143.

28. Karali Y, Saglam H, Karali Z, Kilic SS: The use of complementary and alternative medicine in patients with common variable immunodeficiency. J Invest Allergol Clin/mmunol 2011, 21:480-483.

29. Weissenstein A, Straeter A, Villalon G, Luchter E, Bittmann S: High Frequency of CAM Use Among Children in Germany. J Altern Complement Med 2012, 18(8):1-2.

30. Siponen SM, Ahonen RS, Kettis A, Hämeen-Anttila KP: Complementary or alternative? Patterns of complementary and alternative medicine (CAM) use among Finnish children. Eur J ClinPharmacol 2012, May 10. [Epub ahead of print].

31. Crawford NW, Cincotta DR, Lim A, Powell CV: A cross-sectional survey of complementary and alternative medicine use by children and adolescents attending the University Hospital of Wales. BMC Complement Altern Med 2006, 2:6-16.

32. Trapani G, Barbato C, Zanino L, Del Giudice A: Liverani.Uso delle Medicine Non Convenzionali nella popolazione pediatrica dell'talia Nord-Occidentale. www.smbitalia.org/notizie/articoli/19.htm.

33. Linee guida per la formazione nelle medicine e pratiche non convenzionali riservate ai medici chirurghi e odontoiatri della FNOMCEO. Consiglio Nazionale FNOMCEO - 12 dicembre 2009. www.fnomceo.it.

34. Rosenthal R, Rabin DB: Interpersonal expectancy effects: the first 345 studies. Behav Brain Sci 1978, 1:377-86.

35. Phillips DL, Clancy KJ: "'Modeling effects' in survey research.". Public Opinion Quaterly 1972, 36:246-253.

36. Toupin April K, Moher D, Stinson J, Byrne A, White M, Boon H, Duffy CM, Rader T, Vohra S, Tugwell P: Measurement properties of questionnaires assessing complementary and alternative medicine use in pediatrics: a systematic review. PLoSOne 2012, 7(6):e39611. Epub 2012 Jun 29.

37. Miniero R, Filippo M, Oliverio AC, Zurlo F, Savino F, Oggero R, Altomare F, Dolceamore TR: Indagine conoscitiva sull'impiego delle medicine alternative - complementari in ambito pediatrico: studio interregionale., . In press.Minerva Pediatrica 2012.

38. O'Keefe M, Coat S: Increasing health-care options: the perspectives of parents who use complementary and alternative medicines. J Paediatr Child Health 2010, 46:296-300. G.P.

39. Salvioli GP: I pediatri Italiani e le medicine complementari. Pediatria 2011 , $1: 4-5$.

40. Yussman SM, Ryan SA, Auinger P, Weitzman M: Visit to complementary and alternative medicine providers by children and adolescents in the United States. Ambul Pediatr 2004, 4:429-35.

41. Vantini I, Caruso C, Craxi A: L'insegnamento delle Medicine Alternative e Complementari (CAM) nel Corso di Laurea Magistrale in Medicina e Chirurgia.-Posizione della Conferenza Permanente dei Presidi dei CLM Quaderni dellle Conferenze Permanenti delle Facoltà di Medicina e Chirurgia. 2011, 53:2331-2332.

42. Ben-Arye E, Traube Z, Schachter L, Haimi M, Levy M, Schiff E, Lev E: Integrative pediatric care: parents' attitudes toward communication of physicians and CAM practitioners. Pediatrics 2011, 127:e84-95.

43. Giannelli M, Cuttini M, Da Frè M, Buiatti E: General practioners' knowledge and practice of complementary/alternative medicine and its relationship with life-styles: a population- based survey in Italy. BMC Fam Pract 2007, 8:30-38.

doi:10.1186/1824-7288-38-70

Cite this article as: Dolceamore et al: Use of alternative-

complementary-medicine (CAM) in Calabrian children. Italian Journal of Pediatrics 2012 38:70. 